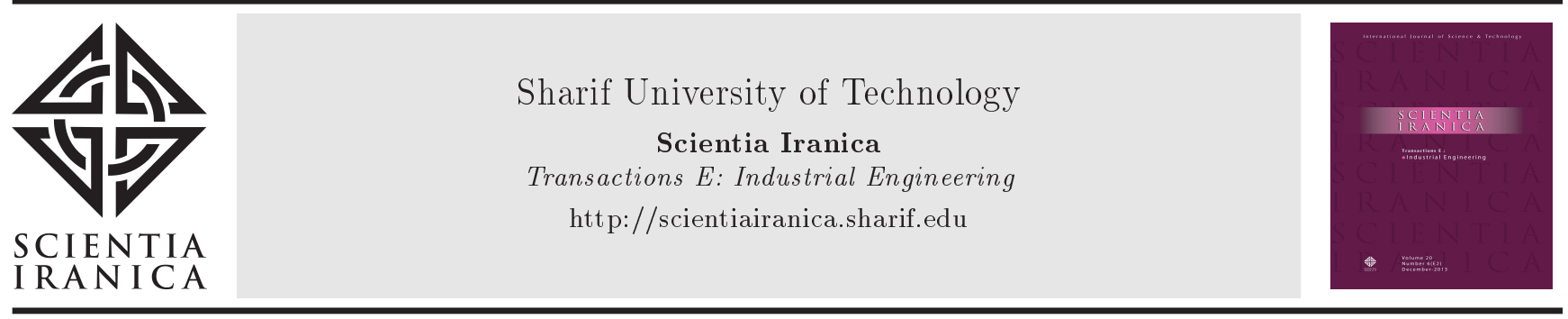

\title{
A novel robust possibilistic cellular manufacturing model considering worker skill and product quality
}

\author{
A. Hashemoghli, I. Mahdavi*, and A. Tajdin \\ Department of Industrial and Systems Engineering, Mazandaran University of Science and Technology, Babol, Iran.
}

Received 3 August 2017; received in revised form 17 October 2017; accepted 16 April 2018

\section{KEYWORDS}

Quality management;

Cellular

manufacturing

problem;

Worker flexibility;

Route flexibility;

Worker skills;

Robust possibilistic

programming.

\begin{abstract}
Design of an appropriate Cellular Manufacturing System (CMS) leads to system flexibility and production efficiency by using the similarities in the manufacturing process of products. One of the main issues in these systems is to consider product quality level and worker's skill level in the production process. This study proposes a comprehensive bi-objective possibilistic nonlinear mixed-integer programming model under uncertain environment to design a suitable CMS with the aim of minimizing the total costs and total inaction of workers and machines, simultaneously. In this respect, the demand for each product with a specific quality level and linguistic parameters such as product quality level, worker's skill level, and job hardness level on machines are considered under fuzzy environment. To this end, the robust possibilistic programming approach is tailored to cope with fuzzy impute parameters. Finally, a real case study is provided to show the efficiency and applicability of the proposed model. In this respect, the proposed approach could reduce the total costs by $23.6 \%$ and the total inaction of workers and machines by $11.7 \%$ in comparison with real practice. In addition, the performance of the presented model is demonstrated by comparing the results obtained from the proposed model and actual practice.
\end{abstract}

(C) 2019 Sharif University of Technology. All rights reserved.

\section{Introduction}

The implementation of cellular manufacturing systems has some benefits including setup time reduction, material handling cost saving, quality management, workin-process inventory reduction, and machine utilizing improvement. Thus, some steps that should be taken to design an appropriate Cellular Manufacturing System (CMS) include:

1. Cell formation, which means that a group of prod-

*. Corresponding author. Tel.: +98(11)32190633

E-mail addresses: arash_hashemoghli@yahoo.com (A.

Hashemoghli); irajarash@rediffmail.com (I. Mahdavi);

Ali_tajdin@yahoo.com (A.Tajdin)

doi: $10.24200 /$ sci.2018.4948.1002 ucts with similar jobs are assigned to part families and related machines in machine cells;

2. Group layout, which is established in both intracell (i.e., machines assigned within each cell) and inter-cell (i.e., cells related to one another) layouts;

3. Group scheduling;

4. Resource allocation, that is, to assign humans, tools, and material resources [1-3].

In this paper, the first, second, and forth stages of cellular manufacturing design are studied under the dynamic environment, which is called the Dynamic Cellular Manufacturing System (DCMS) [4]. Hence, the cell formation, group layout, and resource allocation are performed by considering the final quality of the 
product based on the quality level of demand, hardness level of jobs on machines, and skill level of workers.

Rosenblatt [5] first introduced a dynamic programming approach for designing a layout problem. In this respect, Mahdavi et al. [6] proposed an integer mathematical programming model for the design of CMS by considering the features of dynamic system reconfiguration, multi-period production planning, machine capacity, duplicate machines, worker assignment, and available time for workers with the aim of minimizing the backorder and holding costs; machine and reconfiguration costs; hiring, firing, and salary costs; and inter-cell material handling cost. Saxena and Jain [7] presented an integrated dynamic model, which combined some features of existing models including machine breakdown, reliability, production planning, production cost, intra-cell movement, etc., in a single model with the aim of minimizing the total cost. Paydar et al. [8] developed a comprehensive integer linear programming model based on some features such as sequence of operations, multi-period production planning, intra-cell layout, alternative process routing, dynamic system reconfiguration, lot splitting, machine capacity, duplicate machines, and material flow between machines. Kia et al. [9] presented a dynamic mixed integer non-linear programming model to design a group layout of CMS based on the production planning decisions.

In classical cell formation methods, cells are designed and then, workers are assigned to the cells, while relationships between jobs to skills and skills to workers are ignored. In addition, skill level of workers can be related to hardness of jobs on machines. Therefore, considering skill level of workers regarding the hardness of jobs may be a main factor in worker/machine assignment. In this respect, a few researchers have focused on humans'/workers' skill level for solving cellular manufacturing problems.

Norman et al. [10] proposed a mixed integer programming model for assigning the workers to manufacturing cells based on the their skills to maximize the efficiency of the organization. Suksawat et al. [11] proposed a novel approach by considering the skilled workers-based scheduling technique to solve their manufacturing cell problem. Duan et al. [12] proposed an assembly system based on cellular manufacturing features and considered the workers' skill, collaboration between worker and machine, assembly information guidance, and safe design for collaboration. Egilmez et al. [13] presented an optimization approach with skillbased worker allocation, in which the performance of each worker was considered for more accurate worker allocation to the manufacturing cells with the aim of maximizing the rate of production. The survey of the studies on the worker skills in CMS problems shows that poor attention has been paid to this area.
Thus, this paper considers the worker skill level for allocation of the worker to the machine with specific job hardness level. Lim et al. [14] presented multi-objective hybrid algorithms for layout optimization in multirobot assembly for solving the cellular manufacturing problems. Rezazadeh and Khiali-Miab [15] developed a novel mathematical model for designing the reliable cellular manufacturing systems, which led to decrease in manufacturing costs, improved total reliability of the manufacturing system, and improved product quality. In addition, a two-layer genetic algorithm was presented to address the complexity of cell formation problems to obtain near optimal solutions. Aalaei and Davoudpour [16] proposed a novel mathematical programming model for a CMS along with supply chain design regarding labor assignment with the aim of minimizing the total cost of holding, inter-cell material handling, external transportation, fixed cost for producing each part in each plant, and machine and labor salaries. Forghani and Mohammadi [17] presented an integrated approach to solving the layout problems and cell formation, simultaneously.

Considering the real-world complexity of cellular manufacturing problems, some important parameters (e.g., product demand, processing time, product mix, available machine capacity, and inter-arrival time) are difficult to determine precisely. To address this issue, these parameters should be defined as inputs to the model under uncertainty to cope with imprecise conditions in cellular manufacturing. Different approaches have been developed to deal with the uncertainty, including fuzzy programming, stochastic programming, and robust optimization approach $[18,19]$.

In fuzzy environment, Safaei and Tavakkolimoghaddam [20] developed a mixed-integer programming model to solve the manufacturing problems under uncertainty and dynamic situations. In their study, product demand and machine capacity were considered as fuzzy parameters. Kia et al. [21] proposed a new integer non-linear programming model under fuzzy environment to solve the layout design of dynamic CMS. Behret and Satoglu [22] surveyed the fuzzy methods, especially fuzzy programming and fuzzy clustering, and employed them in the design of CMS. In their study, product demand, inter-cell flow cost, and machine purchasing were considered under uncertain situation. Paydar and Saidi-Mehrabad [23] extended a novel bi-objective possibilistic mathematical model for integrating production, procurement, and distribution planning by considering the uncertain nature of some significant parameters such as machine capacity and customers' demands.

Hence, Tavakkoli-Moghaddam et al. [24] developed a novel mathematical model to solve the facility layout problem in CMS with stochastic demands with the aim of minimizing the total costs of in- 
tra and inter-cell movements. Ghezavati and SaidiMehrabad [25] implemented a scenario-based stochastic programming method to solve the integrated cell formation and group scheduling decision. Ghezavati and Saidi-Mehrabad [26] presented a cellular manufacturing model in which arrival and processing times of products were stochastic. They solved the imprecise problem by applying a queuing-based analysis. Egilmez et al. [27] proposed a stochastic non-linear programming model to solve a cell formation problem in which processing times and product demand were uncertain. Salarian et al. [28] considered the processing time, product demand, and inter-arrival time for product as stochastic parameters in solving the CMS problems. Bagheri et al. [29] proposed a novel dynamic mathematical model for CMS regarding production factors such as machine reliability and alternative process routing with stochastic service and arrival times. Rabbani et al. [30] focused on manpower allocation and cell loading problems with the aim of manpower allocation to cellular manufacturing with consideration of training and learning policies when demand was stochastic.

In addition, employing the robust optimization, Ghezavati et al. [31] presented a novel mathematical robust optimization model for a CMS integrated with tactical aspects regarding supply chain network features in the presence of imprecise processing time and demand parameters. Forghani et al. [32] provided a novel robust optimization approach to address data uncertainty. In their study, an interval approach unlike the scenario-based approaches was regarded to handle demand imprecision in the process of layout design and cell formation. Tavakkoli-Moghaddam et al. [33] developed a robust mathematical programming model to solve a CMS integrated with production planning under dynamic and uncertainty environments. Sakhaii et al. [34] presented a robust optimization approach for a novel integrated dynamic mixed-integer programming model under imprecise nature parameters to solve the CMS with production planning and unreliable machines problems, simultaneously. Review of the literature that has employed the robust optimization in CMS problems shows that considering the robust optimization approach to deal with uncertainty is more interested.

In this paper, a nonlinear mixed-integer programming model is developed under uncertainty and dynamic environments. In addition, the quality of products is managed during the operation process based on worker's skill and job hardness levels on machines. Table 1 summarizes the cellular manufacturing models and methods developed based on some features such as cell formation, worker/machine assignment, job hardness level on machines, and worker's skill level. As presented in Table 1, the features of job hardness and product quality levels have not been considered by authors in the recent literature. Also, other features such as worker's skill level as well as worker flexibility and uncertainty have received less attention in the related literature. In this regard, only two studies have developed the mathematical models by considering workers' skill level among others. In addition, most of the earlier studies have considered the cell formation, machine allocation, route flexibility, machine capacity, and multi-period features to solve their CMS problems. By proposing a nonlinear mixed-integer programming model, this research attempts to fill in this gap in the CMS literature.

The rest of this paper is outlined as follows: Section 2 presents the proposed model based on the problem description and assumptions. In Section 3, the proposed approach to solving the developed model is provided. Then, a case study is considered to show the validity of the proposed approach in Section 4. Furthermore, sensitivity analysis is provided in Section 5 to present the robustness and sensitiveness of results. Finally, some concluding remarks and future directions are presented in Section 6.

\section{Proposed model}

In this section, a novel mixed-integer nonlinear programming model is presented under the dynamic environment to solve cell manufacturing problems. First, the problem description is presented in detail and then, assumptions considered for modeling the proposed approach are presented.

\subsection{Problem description}

The cellular manufacturing problem, which is considered in this paper, is shown in Figure 1. To address the issue, a number of cells $(k)$ and machines $(m)$, which operate some specific jobs $(j)$ for different products $(p)$ by workers $(w)$, are provided. Each worker has a specific skill $(s)$ regarding hardness of jobs on machines $(h)$, which leads to a specific product quality level $(q)$. Also, each machine has a certain capacity $\left(M L_{m}\right)$ and each product is produced under uncertain processing

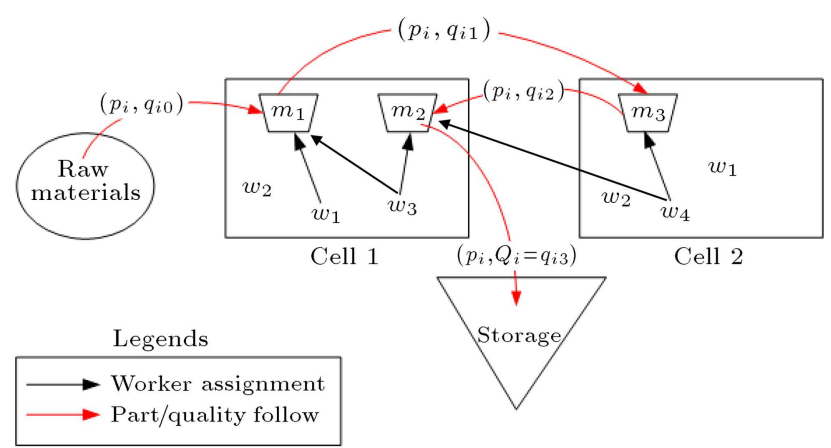

Figure 1. The structure of the cellular manufacturing problem regarding the product quality level. 


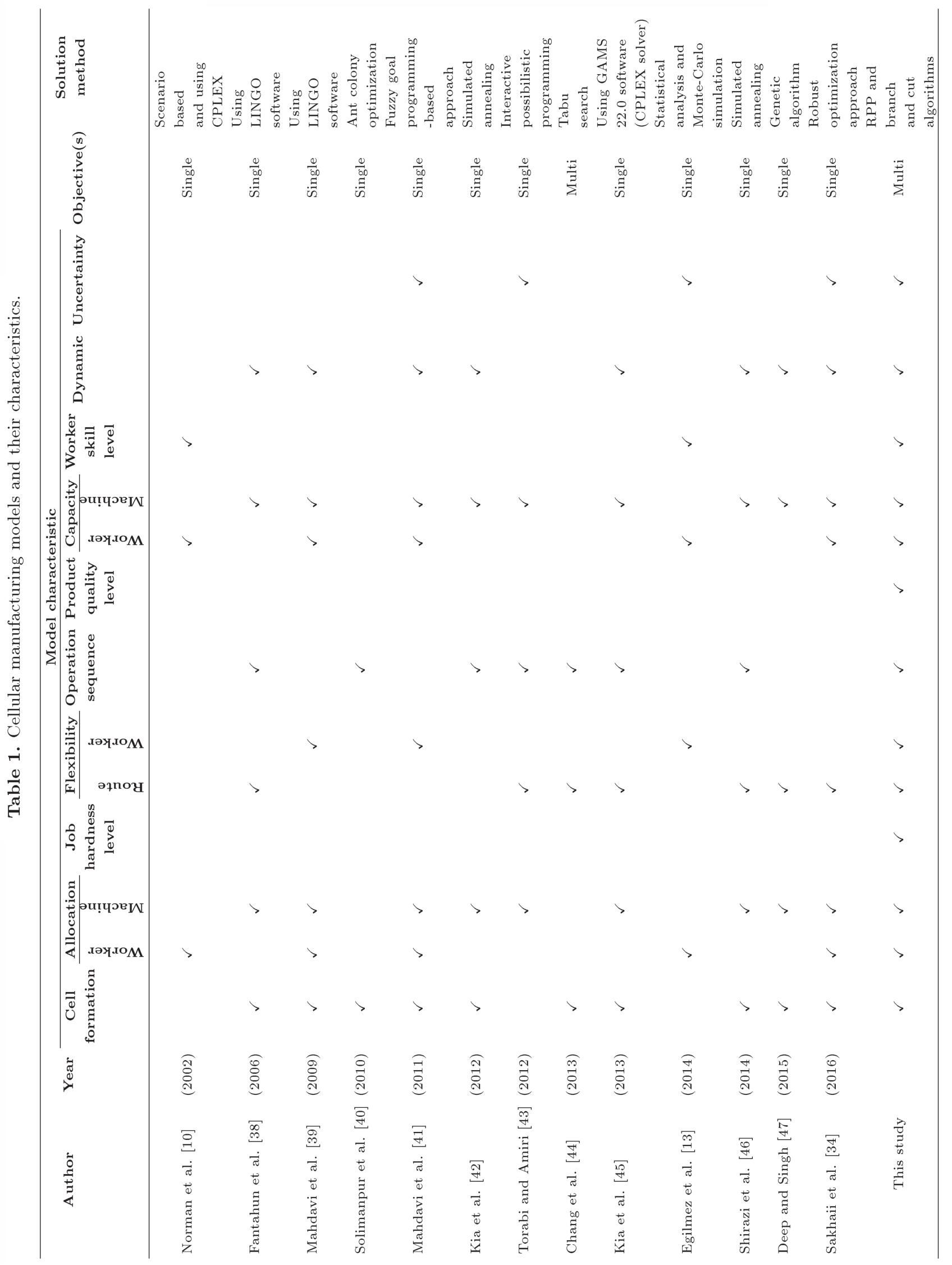


time $\left(P T_{j w m}\right)$. In addition, the number of cells $(N C)$ must be specified and the minimum $(N L)$ and maximum $(N U)$ numbers of machines in each cell are determined by a decision maker or user of the model. Hence, each worker has an available time to work $\left(W L_{w}\right)$, which must satisfy the minimum work time $\left(L W L_{w}\right)$ and maximum work time $\left(L M L_{m}\right)$. In addition, the demand of each customer by a specific quality level $\left(d_{p q}^{t}\right)$ is achieved at the start of each period $(t)$. In this respect, the output quality level of the produced products $\left(\lambda_{O_{j p m}}^{w}\right)$ is affected by job hardness on machines $\left(H_{j m}\right)$ and workers' skills $\left(S_{w m}^{s}\right)$, and the final quality level of products is determined based on the minimum quality level of processes of produced products. In a certain situation, the linguistic variables of product quality, job hardness level on machines, and worker's skills are defined in three levels. In this respect, Table 2 clearly expresses the interaction between the linguistic variables. However, products require some different operations $\left(O_{j p m}\right)$ in available routing $\left(R_{p}\right)$, which should be processed in an appropriate route $\left(\theta_{r p}^{t}\right)$ with regard to assigning products to a cell $\left(Y_{j p m}^{k}\right)$ and to a machine $\left(\xi_{j p m}^{h}\right)$. Hence, each product has a material flow conservation and concatenated production sequence $\left(V_{j p k k^{\prime}}^{m m^{\prime}}\right)$. In addition, if one cell is established $\left(C F_{k}\right)$, machines could be allocated to cells $\left(X_{m k}\right)$ and workers could be assigned to machines $\left(Z_{w j m}^{t}\right)$ regarding their skill level $\left(\varpi_{w j m}^{s}\right)$. However, the proposed model is formulated with the aim of minimizing total costs, including cost of worker employment $\left(C W_{w}^{s}\right)$, processing cost of machines $\left(C M_{m}^{h}\right)$, fixed cost of establishing each cell $\left(C C_{k}\right)$, intra-cell movement cost of cells $\left(C I_{k}\right)$, and inter-cell movement cost between cells $\left(C O_{k k^{\prime}}\right)$, and the total inaction of workers and machines.

Table 2 demonstrates that a worker with a specific skill level on each machine, which has a specific job hardness level, produces a product with a certain quality level (i.e., best quality $=q_{1}$, moderate quality $=q_{2}$, and worst quality $\left.=q_{3}\right)$. For example, as indicated in Table 2, a beginner worker cannot work on machines with high hardness level, and they will produce a product with moderate quality $\left(q_{2}\right)$ if they work on machines with low hardness level. Hence, qualities of

Table 2. The output quality level of products regarding job hardness and worker skills.

\begin{tabular}{lccc}
\hline \multirow{2}{*}{\begin{tabular}{c} 
Hardness level \begin{tabular}{l} 
of jobs \\
\cline { 2 - 4 }
\end{tabular} \\
\cline { 2 - 4 }
\end{tabular}} & \multicolumn{3}{c}{ Skill level of workers } \\
\hline Beginner & $q_{2}$ & $q_{1}$ & $q_{1}$ \\
Moderate & $q_{3}$ & $q_{2}$ & $q_{1}$ \\
High & - & $q_{3}$ & $q_{1}$ \\
\hline
\end{tabular}

output products manufactured by other workers are evaluated based on the aforementioned procedure.

In real cases, defining the above linguistic variables (i.e., machine hardness level, worker's skill level, and product quality level) is difficult and often vague. Thus, considering the linguistic variables under uncertainty is more suitable and makes the proposed model more applicable in the real world.

\subsection{Assumptions}

The proposed dynamic non-linear mixed integer programming model with the aim of minimizing the total costs and inaction of workers and machines is formulated under the following assumptions:

1. Each product must be assigned to only one cell;

2. Each machine must be assigned to only one cell;

3. Each product has a number of process routings, which could be selected among the available routs;

4. A lower bound for workers load and machines load must be satisfied;

5. The working capacity is considered for each machine and worker;

6. The hardness of job is not related to each product;

7. The quality of the product is defined based on the linguistic variables;

8. The hardness of jobs on the machine is determined based on linguistic terms;

9. The skill level of each worker is specified based on linguistic variables;

10. Each product has a number of jobs that must be processed based on its jobs sequence;

11. The processing time of all jobs for a product on each machine is known;

12. The operation cost of each machine and the working cost of each worker per minutes are known;

13. The processing time of each product can be different in various machines (routing flexibility);

14. Minimum and maximum numbers for each machine, which could be assigned to a cell, are known;

15. There is an only one type of each machine;

16. Inventory is not allowable.

\subsection{Notations}

The notations including sets, parameters, and decision variables are defined as follows:

Sets

$p \quad$ Index of products, $p=1,2, \cdots, P$;

$m, m^{\prime} \quad$ Index of machines, $m=1,2, \cdots, M$, $m^{\prime}=1,2, \cdots, M^{\prime}$; 
$w \quad$ Index of workers, $w=1,2, \cdots, W$;

$t \quad$ Index of periods, $t=1,2, \cdots, T$;

$j \quad$ Index of jobs, $j=1,2, \cdots, J$;

$s \quad$ Index of skills, $s=1,2, \cdots, S$;

$h \quad$ Index of hardness, $h=1,2, \cdots, H$;

$q \quad$ Index of quality, $q=1,2, \cdots, Q$;

$k, k^{\prime} \quad$ Index of cells, $k=1,2, \cdots, K$, $k^{\prime}=1,2, \cdots, K^{\prime}$;

$r \quad$ Index of routes, $r=1,2, \cdots, R$.

\section{Parameters}

$R_{p} \quad$ Number of available routings for product $p$;

$S_{w m}^{s} \quad$ The skill level $s$ of worker $w$ on machine $m$;

$H_{j m}^{h} \quad$ The hardness level $h$ of job $j$ on machine $m$;

$O_{j p m} \quad$ The required job $j$ for product $p$ that needs to be processed by machine $m$;

$\lambda_{O_{j p m}}^{w} \quad$ The output quality $q$ of required job $j$ for product $p$ by worker $w$ on machine $m$;

$d_{p q}^{t} \quad$ The demand of product $p$ with quality $q$ at period $t$

$d b_{p q}^{t} \quad d b_{p q}^{t}=\left\{\begin{array}{ll}1 & d_{p q}^{t}>0 \\ 0 & d_{p q}^{t}=0\end{array} \quad \forall p, q, t\right.$

$C W_{w}^{s} \quad$ The cost of employing worker $w$ with the skill level of $s$;

$C M_{m j}^{h} \quad$ The processing cost of machine $m$ with hardness level $h$ for job $j$;

$C C_{k} \quad$ Fixed cost of establishing each cell;

$C I_{k} \quad$ The intra-cell movement cost of cell $k$;

$C O_{k k^{\prime}} \quad$ The inter-cell movement cost of cell $k$ to cell $k^{\prime}$;

$W L_{w}^{t} \quad$ The load of worker $w$ with regards to the available time;

$M L_{m}^{t} \quad$ The load of machine $m$ with regards to the available time;

$P T_{\text {jwm }} \quad$ Processing time of job $j$ done by worker $w$ on machine $m$;

NL Minimum number of machines in each cell;

NU Maximum number of machines in each cell;

$N C \quad$ Number of cells that should be formed;

$L W L_{w}^{t} \quad$ The lower bound of worker load for worker $k$;

$L M L_{m}^{t} \quad$ The lower bound of machine load for machine $m$.
Decision variables

$X_{m k} \quad 1$ if machine $m$ is assigned to cell $k, 0$ otherwise;

$Y_{j p m}^{k q} \quad 1$ if product $p$ with quality level $q$ is processed by job $j$ on machine $m$ in cell $k, 0$ otherwise;

$\xi_{j p m}^{h q} \quad 1$ if product $p$ with quality level $q$ is processed by job $j$ on machine $m$ with hardness $h, 0$ otherwise;

$Z_{w j m} \quad 1$ if worker $w$ is assigned to machine $m$ for job $j, 0$ otherwise;

$\varpi_{w j m}^{s} \quad 1$ if worker $w$ for performing the job $j$ on machine $m$ has skill level $s, 0$ otherwise;

$V_{j p k k^{\prime}}^{m m^{\prime} q} \quad 1$ if job $j+1$ of product $p$ with quality level $q$ is processed by machine $m^{\prime}$ in cell $k^{\prime}$ after performing job $j$ on machine $m$ in cell $k, 0$ otherwise;

$\theta_{r p}^{t} \quad 1$ if route $r$ for product $p$ is selected as the process plan in period $t, 0$ otherwise;

$\operatorname{Pr}_{p q}^{t} \quad$ Amount of product $p$ produced with quality level $q$ in period $t$;

$C F_{k} \quad 1$ if cell $k$ is formed, 0 otherwise;

$P Q_{p q} \quad$ The quality level $q$ of product $p$; its value is related to the quality level of produced product is as follows:

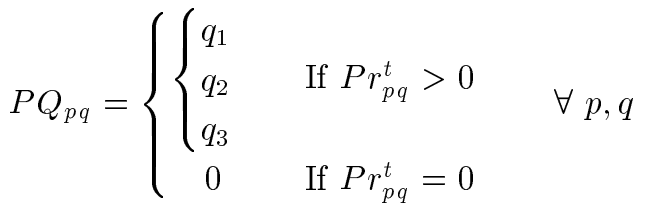

\subsection{Proposed model}

$$
\begin{aligned}
\min Z_{T C} & =\left(\sum_{j=1}^{J} \sum_{p=1}^{P} \sum_{q=1}^{Q} \sum_{m=1}^{M} \sum_{k=1}^{K} C I_{k} Y_{j p m}^{k q}\right. \\
& \left.+\sum_{j=1}^{J} \sum_{p=1}^{P} \sum_{q=1}^{Q} \sum_{m=1}^{M} \sum_{m^{\prime}=1}^{M^{\prime}} \sum_{k=1}^{K} \sum_{k^{\prime}=1}^{K^{\prime}} C O_{k k^{\prime}} V_{j p k k^{\prime}}^{m m^{\prime} q}\right) \\
& +\left(\sum_{s=1}^{S} \sum_{w=1}^{W} \sum_{j=1}^{J} \sum_{m=1}^{M} \varpi_{w j m}^{s} C W_{w}^{s}\right) \\
& +\left(\sum_{j=1}^{J} \sum_{p=1}^{P} \sum_{q=1}^{Q} \sum_{m=1}^{M} \sum_{h=1}^{H} \xi_{j p m}^{h q} C M_{m j}^{h}\right) \\
& +\left(\sum_{k=1}^{K} C C_{k} C F_{k}\right),
\end{aligned}
$$




$$
\begin{aligned}
\min Z_{I A} & =\left(\sum_{t=1}^{T} \sum_{w=1}^{W} W L_{w}^{t}\right. \\
& \left.-\sum_{w=1}^{W} \sum_{j=1}^{J} \sum_{m=1}^{M} P T_{j w m} Z_{w j m}\right) \\
& +\left(\sum_{t=1}^{T} \sum_{m=1}^{M} M L_{m}^{t}\right. \\
& \left.-\sum_{k=1}^{K} \sum_{w=1}^{W} \sum_{p=1}^{P} \sum_{q=1}^{Q} \sum_{m=1}^{M} \sum_{j=1}^{J} P T_{j w m} Y_{j p m}^{k q}\right),
\end{aligned}
$$

$\sum_{k=1}^{K} X_{m k} C F_{k}=1$

$\forall m$,

$N L \leq \sum_{k=1}^{K} \sum_{m=1}^{M} X_{m k} C F_{k} \leq N U, \quad \forall m, k$,

$\sum_{k=1}^{K} C F_{k} \leq N C$

$\forall k$,

$$
\begin{aligned}
L M L_{m}^{t} & \leq \sum_{k=1}^{K} \sum_{p=1}^{P} \sum_{q=1}^{Q} \sum_{j=1}^{J} \sum_{w=1}^{W} \sum_{r=1}^{R} P T_{j w m} Y_{j p m}^{k q} \theta_{r p}^{t} \\
& \leq M L_{m}^{t}, \\
& \forall m, t,
\end{aligned}
$$$$
L W L_{w}^{t} \leq \sum_{j=1}^{J} \sum_{m=1}^{M} P T_{j w m} Z_{w j m} \leq W L_{w}^{t}, \quad \forall w, t
$$$$
\sum_{t=1}^{T} \sum_{q=1}^{Q} d_{p q}^{t}=\sum_{t=1}^{T} \sum_{q=1}^{Q} \operatorname{Pr}_{p q}^{t}, \quad \forall p,
$$$$
\operatorname{Pr}_{p q}^{1} \leq d_{p q}^{1}, \quad \forall p, q,
$$

$P r_{p q}^{t} \leq d_{p q}^{t}+\sum_{t=2}^{T-1}\left(d_{p q}^{t-1}-P r_{p m q}^{t-1}\right), \quad \forall p, q, t \geq 2$

$$
\sum_{k=1}^{K} \sum_{m=1}^{M} Y_{j p m}^{k q} O_{j p m}=d b_{p q}^{t}, \quad \forall j, p, q, t,
$$$$
\sum_{h=1}^{H} \xi_{j p m}^{h q} \geq Y_{j p m}^{k q}, \quad \forall j, p, q, m, k,
$$

$\sum_{j=1}^{J} \sum_{p=1}^{P} \sum_{q=1}^{Q} \sum_{m=1}^{M} H_{j m}^{h} \xi_{j p m}^{h q} \geq \sum_{w=1}^{W} \sum_{m=1}^{M} \lambda_{O_{j p m}}^{w}$,

$\forall j, p, h$,

$$
\begin{aligned}
& \sum_{s=1}^{S} \varpi_{w j m}^{s} \geq Z_{w j m} \\
& \sum_{w=1}^{W} \sum_{j=1}^{J} \sum_{m=1}^{M} S_{w m}^{s} \varpi_{w j m}^{s} \geq \sum_{w=1}^{W} \sum_{m=1}^{M} \lambda_{O_{j p m}}^{w}, \\
& \forall j, p, s, \\
& \sum_{w=1}^{W} \sum_{m=1}^{M} \sum_{j=1}^{J} \lambda_{O_{j p m}}^{w} \varpi_{w j m}^{s} \xi_{j p m}^{h q} \geq P Q_{p q}, \\
& \forall p, q, s, h, \\
& Y_{j p m}^{k q}+Y_{(j+1) p m^{\prime}}^{k^{\prime} q}-2 V_{j p k k^{\prime}}^{m m^{\prime} q} \geq 0, \\
& \forall j, p, q, m, m^{\prime}, k, k^{\prime}, \\
& Y_{j p m}^{k q}+Y_{(j+1) p m^{\prime}}^{k^{\prime} q}-V_{j p k k^{\prime}}^{m m^{\prime} q} \leq 1 \\
& \forall j, p, q, m, m^{\prime}, k, k^{\prime}, \\
& \sum_{r=1}^{R_{p}} \theta_{r p}^{t}=d b_{p q}^{t}, \quad \forall p, q, t, \\
& P Q_{p q}, P r_{p q}^{t} \geq 0 \\
& X_{m k}, Y_{j p m}^{k q}, \xi_{j p m}^{h q}, Z_{w j m}, \varpi_{w j m}^{s}, V_{j p k k^{\prime}}^{m m^{\prime} q}, C F_{k}, \theta_{r p}^{t} \\
& \in\{0,1\} \text {. } \\
& \forall w, j, m \text {, }
\end{aligned}
$$

The objective function (1) is to minimize the total costs, in which the first term is the intra- and intercell movements costs, the second term is the cost of employing workers regarding their skill levels, the third term is the processing cost of machines regarding their hardness, and the fourth term is related to the fixed cost of constructing cells. The objective function (2) minimizes the total inaction of workers and machines, simultaneously.

Constraints (3) and (4) determine that each machine could be assigned to only one cell and identify the minimum and maximum numbers of machines which should be located in each cell, respectively. Constraint (5) ensures the maximum number of cells that could be formed. Constraints (6) and (7) ensure that the minimum and maximum machine loads and worker loads must be satisfied, respectively. Constraint (8) ensures that the demand for each product must be satisfied within the periods. Constraints (9) and (10) denote that excess production is not allowed. Constraint (11) guarantees that each production job is assigned to one machine and one cell. Constraint (12) determines the reactions to the job assignments regarding machine 
hardness. Constraint (13) expresses that the machine with lower hardness should be selected. Constraint (14) assures that the worker is assigned to the machine for the specific job when they have the minimum skill level for that specific job. Constraint (15) denotes that the appropriate worker with suitable skill level is selected to produce the product with the best quality level. Constraint (16) establishes the relationship between the product quality level, which should be produced, and the skill level of workers and the hardness of machines. Constraints (17) and (18) ensure the material flow conservation and guarantee that all consecutive jobs of a product involve a concatenated production sequence, resulting in complete processing of the products. Constraint (19) shows that only one process routing must be selected. Relations (20) and (21) indicate the integer and binary variables, respectively.

\section{Proposed solution approach}

In this section, the proposed solution approach is presented to solve the proposed model as well as to deal with uncertain parameters. In this respect, the compact model, which enhances the presentation of the solution approach, is the following:

$$
\begin{aligned}
& f_{1}(x): C_{1} Y, \\
& f_{2}(x): C_{2} Y, \\
& A_{1} Y Z=B_{1}, \\
& A_{2} Y Z \leq B_{2}, \\
& A_{3} Y Z \geq B_{3}, \\
& P_{1} Y \leq B_{4}, \\
& P_{2} Y \geq B_{5}, \\
& R_{1} X=B_{6}, \\
& R_{2} X \leq B_{7}, \\
& P_{3} Y=B_{8}, \\
& A_{4} Y Z-R_{3} X \geq B_{9}, \\
& P_{4} Y-P_{5} Z \geq B_{10}, \\
& X \geq 0, \quad Y, Z \in\{0,1\} .
\end{aligned}
$$

Relations (22) and (23) represent the objective functions of the propose model. Constraint (24) is related to Constraint (3), and Constraints (25) and (26) correspond to Constraints (4) and (6). In addition, Constraint (27) is related to Constraints (5), (7), and (18) and Constraint (28) corresponds to Constraints (7), (13), (15), and (17). In this respect, Constraint (29) is related to Constraint (8), Constraint (30) corresponds to Constraints (9) and (10), and Constraint (31) corresponds to Constraints (11) and (19). Also, Constraint (32) relates to Constraint (16). In addition, Constraint (33) corresponds to Constraints (12) and (14). Finally, Constraint (34) determines that the $X$ vector is positive variable and the $Y$ and $Z$ vectors are binary variables.

To solve the proposed bi-objective mixed-integer non-linear mathematical model, three phases should be tailored:

I) The well-known linearization approach represented by Paydar and Saidi-Mehrabad [35] is utilized to obtain a linear model;

II) The possibilistic programming approach first introduced by Pishvaee et al. [36] is applied to deal with uncertainty;

III) An efficient simple augmented e-constraint technique introduced by Zhang and Reimann [37] is implemented to convert the proposed bi-objective model to a single-objective one.

\subsection{Linearization}

As represented in the compact model, Eqs. (24)-(26) and (32) are non-linear. In this regard, some auxiliary variables should be defined and some constraints should be added to the basic model for linearization of the proposed model [35]. In this respect, let $\mathrm{X}$ and $\mathrm{Y}$ be binary variables; then, define $F=X \times Y$, the following variables and constraints are provided to convert the non-linear compact model to a linear one.

$$
\begin{aligned}
& F=X \times Y, \\
& F-X-Y+\varepsilon \geq 0 \\
& \varepsilon \times F-X-Y \leq 0, \\
& X, Y \in\{0,1\} \quad \text { and } \quad 1<\varepsilon<2,
\end{aligned}
$$

where $\varepsilon$ is constant, and $\varepsilon \in \underline{\mathrm{R}}$.

In addition, when a positive variable such as $S$ is multiplied by a binary variable such as $D$, the following auxiliary variable and constrains must be regarded for linearization:

$$
\begin{aligned}
& Z=S \times D \\
& Z \geq S-M(1-D), \\
& Z \leq S+M(1-D), \\
& Z \leq M D
\end{aligned}
$$




$$
S \geq 0, \quad D \in\{0,1\} .
$$

where $M$ is a large positive number.

\subsection{Robust possibilistic programming}

In complex real world, lack of experimental data leads to the uncertainty of the input parameters, which should be considered for solving the imprecise problems. Fuzzy set theory is one of the powerful and convenient tools among scholars to deal with uncertainty.

In the proposed cellular manufacturing model, the nature of some important parameters is imprecise. Thus, considering these uncertain parameters in the procedure of the solution approach could help us to deal with the problem close to real world. Hence, the product demand with a specific quality level is recognized in each period and may change during the planning horizon. Therefore, identifying the customer demand and determining an exact value for it are impossible in real cases. Also, as expressed in the introduction, the processing time of each machine is known as an important parameter in cellular manufacturing problems, which should be considered under uncertainty. In addition, some parameters are defined based on linguistic variables, which should be considered as uncertain parameters, because specifying the values of linguistic parameters is performed vaguely and hesitantly. In this respect, some parameters such as the skill level of workers on each machine, the hardness of each job for each machine, and the output quality of processing procedures are more interesting to consider under imprecision. Consequently, the uncertainty of the proposed cellular manufacturing model is higher than the that of the other developed models with respect to the defined assumption for the presented model. To address the issue, the Robust Possibilistic Programming (RPP) approach is tailored to solve the proposed possibilistic model. In this regard, the trapezoidal possibility distributions are provided to model the uncertain parameters. Considering the aforementioned illustrations, Basic Possibilistic Chance Constraint Programming (BPCCP) can be represented as follows:

$$
\begin{aligned}
& f_{1}(x): C_{1} Y, \\
& E\left(f_{2}(x)\right): E\left(\tilde{C}_{2}\right) Y, \\
& \operatorname{Nec}\left(\tilde{A}_{2} F \leq B_{2}\right) \geq \alpha_{1}, \\
& \operatorname{Nec}\left(\tilde{A}_{3} F \geq B_{3}\right) \geq \alpha_{2}, \\
& \operatorname{Nec}\left(\tilde{P}_{1} Y \leq \tilde{B}_{4}\right) \geq \alpha_{3},
\end{aligned}
$$

$$
\begin{aligned}
& \operatorname{Nec}\left(\tilde{P}_{2} Y \geq \tilde{B}_{5}\right) \geq \alpha_{4}, \\
& \operatorname{Nec}\left(R_{1} X=\tilde{B}_{6}\right) \geq \beta_{1}, \\
& \operatorname{Nec}\left(R_{2} X \leq \tilde{B}_{7}\right) \geq \alpha_{5}, \\
& \operatorname{Nec}\left(\tilde{A}_{4} F-R_{3} X \geq B_{9}\right) \geq \alpha_{6}, \\
& X \geq 0, \quad F, Y \in\{0,1\}, \quad \text { and } \\
& 0.5<\alpha_{1}, \alpha_{2}, \alpha_{3}, \alpha_{4}, \alpha_{5}, \alpha_{6}, \alpha_{7}, \beta_{1} \leq 1 .
\end{aligned}
$$

To meet the requirements of the aforementioned constraints, Eqs. (46)-(52), (54) and (55) drawn from Figure 2, and Eqs. (56) and (57) obtained from Figure 3 should be considered.

$$
\begin{aligned}
& N e c(\tilde{A} x \leq B)=1-\sup _{t>k}\left(\mu_{A}(t)\right), \\
& \operatorname{Nec}(\tilde{A} x \leq B)= \begin{cases}0 & t<A_{3} \\
\frac{t-A_{3}}{A_{4}-A_{3}} & A_{3} \leq t<A_{4} \\
1 & t>A_{4}\end{cases} \\
& N e c(A x \leq \tilde{B})=1-\sup _{t<k}\left(\mu_{B}(t)\right), \\
& N e c(A x \leq \tilde{B})= \begin{cases}0 & t \geq B_{2} \\
\frac{B_{2}-t}{B_{2}-B_{1}} & B_{1} \leq t<B_{2} \\
1 & t<B_{1}\end{cases}
\end{aligned}
$$

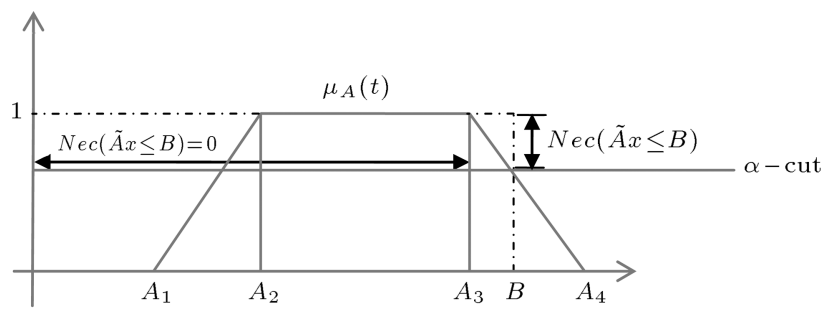

Figure 2. Necessity measure for $t>k$.

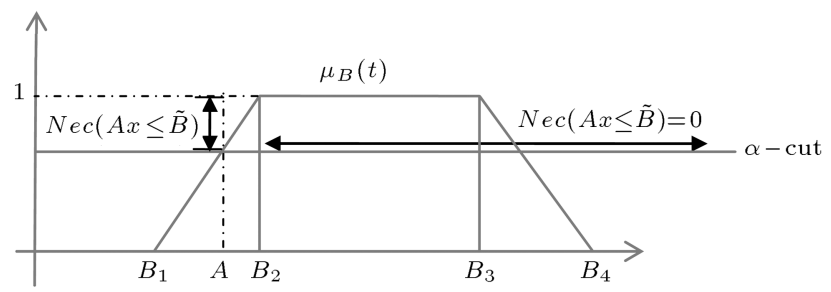

Figure 3. Necessity measure for $t<k$. 
Therefore, the BCCP model could be reformulated as follows:

$$
\begin{aligned}
& f_{1}(x): C_{1} Y \\
& E\left(f_{2}(x)\right): E\left(\frac{c_{2(1)}+c_{2(2)}+c_{2(3)}+c_{2(4)}}{4}\right) Y, \\
& \left(\alpha_{1} A_{2(4)}+\left(1-\alpha_{1}\right) A_{2(3)}\right) F \leq B_{2}, \\
& \left(\alpha_{2} A_{3(1)}+\left(1-\alpha_{2}\right) A_{3(2)}\right) F \geq B_{3}, \\
& \left(\alpha_{3} P_{1(4)}+\left(1-\alpha_{3}\right) P_{1(3)}\right) Y \leq \alpha_{3} B_{4(1)}+\left(1-\alpha_{3}\right) B_{4(2)}, \\
& \left(\alpha_{4} P_{2(1)}+\left(1-\alpha_{4}\right) P_{2(2)}\right) Y \geq \alpha_{4} B_{5(4)}+\left(1-\alpha_{4}\right) B_{5(3)}, \\
& R_{1} X \leq \frac{\beta_{1}}{2} B_{6(3)}+\left(1-\frac{\beta_{1}}{2}\right) B_{6(4)}, \\
& R_{1} X \geq \frac{\beta_{1}}{2} B_{6(2)}+\left(1-\frac{\beta_{1}}{2}\right) B_{6(1)}, \\
& R_{2} X \leq \alpha_{5} B_{7(1)}+\left(1-\alpha_{5}\right) B_{7(2)}, \\
& \left(\alpha_{6} A_{4(1)}+\left(1-\alpha_{6}\right) A_{4(2)}\right) F-R_{3} X \geq B_{9}, \\
& X \geq 0, \quad F, Y \in\{0,1\}, \quad \text { and } \\
& 0.5<\alpha_{1}, \alpha_{2}, \alpha_{3}, \alpha_{4}, \alpha_{5}, \alpha_{6}, \beta_{1} \leq 1 .
\end{aligned}
$$

Consequently, the robust possibilistic programming model is obtained as follows:

$$
\begin{aligned}
& f_{1}(x): C_{1} Y \\
& E\left(f_{2}(x)\right)+\delta\left(f_{2 \max }(x)-f_{2 \min }(x)\right) \\
& \quad+\psi_{1}\left[A_{2(4)}-\alpha_{1} A_{2(4)}-\left(1-\alpha_{1}\right) A_{2(3)}\right] \\
& \quad+\psi_{2}\left[\alpha_{2} A_{3(1)}+\left(1-\alpha_{2}\right) A_{3(2)}-A_{3(1)}\right] \\
& \quad+\psi_{3}\left[P_{1(4)}-\alpha_{3} P_{1(4)}-\left(1-\alpha_{3}\right) P_{1(3)}\right] \\
& \quad+\psi_{4}\left[\alpha_{3} B_{4(1)}+\left(1-\alpha_{3}\right) B_{4(2)}-B_{4(1)}\right] \\
& +\psi_{5}\left[\alpha_{4} P_{2(1)}+\left(1-\alpha_{4}\right) P_{2(2)}-P_{2(1)}\right] \\
& +\psi_{6}\left[B_{5(4)}-\alpha_{4} B_{5(4)}-\left(1-\alpha_{4}\right) B_{5(3)}\right] \\
& +\psi_{7}\left[\alpha_{5} B_{7(1)}+\left(1-\alpha_{5}\right) B_{7(2)}-B_{7(1)}\right] \\
& +\psi_{8}\left[\alpha_{6} A_{4(1)}+\left(1-\alpha_{6}\right) A_{4(2)}-A_{4(1)}\right]
\end{aligned}
$$

$$
\begin{aligned}
& +\ell_{1}\left[\frac{\beta_{1}}{2} B_{6(3)}+\left(1-\frac{\beta_{1}}{2}\right) B_{6(4)}-B_{6(3)}\right] \\
& +\ell_{1}\left[B_{6(2)}-\frac{\beta_{1}}{2} B_{6(2)}-\left(1-\frac{\beta_{1}}{2}\right) B_{6(1)}\right] \text {, } \\
& \left(\alpha_{1} A_{2(4)}+\left(1-\alpha_{1}\right) A_{2(3)}\right) F \leq B_{2}, \\
& \left(\alpha_{2} A_{3(1)}+\left(1-\alpha_{2}\right) A_{3(2)}\right) F \geq B_{3}, \\
& \left(\alpha_{3} P_{1(4)}+\left(1-\alpha_{3}\right) P_{1(3)}\right) Y \leq \alpha_{3} B_{4(1)}+\left(1-\alpha_{3}\right) B_{4(2)}, \\
& \left(\alpha_{4} P_{2(1)}+\left(1-\alpha_{4}\right) P_{2(2)}\right) Y \geq \alpha_{4} B_{5(4)}+\left(1-\alpha_{4}\right) B_{5(3)} \\
& R_{1} X \leq \frac{\beta_{1}}{2} B_{6(3)}+\left(1-\frac{\beta_{1}}{2}\right) B_{6(4)} \\
& R_{1} X \geq \frac{\beta_{1}}{2} B_{6(2)}+\left(1-\frac{\beta_{1}}{2}\right) B_{6(1)} \\
& R_{2} X \leq \alpha_{5} B_{7(1)}+\left(1-\alpha_{5}\right) B_{7(2)}, \\
& \left(\alpha_{6} A_{4(1)}+\left(1-\alpha_{6}\right) A_{4(2)}\right) F-R_{3} X \geq B_{9}, \\
& X \geq 0, \quad F, Y \in\{0,1\}, \quad \text { and } \\
& 0.5<\alpha_{1}, \alpha_{2}, \alpha_{3}, \alpha_{4}, \alpha_{5}, \alpha_{6}, \beta_{1} \leq 1,
\end{aligned}
$$

where $f_{2 \min }(x)$ and $f_{2 \max }(x)$ are denoted by $c_{2(1)}$ and $c_{2(4)}$, respectively. As indicated in the aforementioned model, the non-linear RPP model could be linearized.

\subsection{Multi-objective programming}

The proposed bi-objective model is converted to a single-objective one based on efficient simple augmented e-constraint (SAUGMECON) method, which was presented by Zhang and Reimann [37], as follows:

$$
\begin{gathered}
\min \left(f_{1}(x)+\delta\left(\frac{f_{2}(x)}{r_{2}}+\frac{f_{3}(x)}{r_{3}}+\cdots+\frac{f_{p}(x)}{r_{P}}\right)\right) \\
\text { s.t. } f_{2}(x) \leq \varepsilon_{2} \\
f_{3}(x) \leq \varepsilon_{3} \\
\vdots \\
f_{p}(x) \leq \varepsilon_{P} \\
x \in S
\end{gathered}
$$

where $\delta$ is a small number commonly determined between $\left[10^{-3}, 10^{-6}\right]$ and $r_{p}, p \in[1, P]$ is the range of the $p$ th objective. Hence, the SAUGMECON 
method is established by considering the features of both traditional e-constraint and AUGMECON. In this regard, the traditional e-constraint is considered to add some inequalities to the objectives in constraint space and the sum of weighted constraint objectives is combined into an objective function.

\subsection{Exact solution procedure}

In this section, the proposed mixed integer linear programming model is solved utilizing GAMS 22.1 software regarding CPLEX solver. However, the exact solution process considered is the traditional simplex based on branch and cut algorithm, which includes exact algorithms consisting of an approach integrating cutting plane method and branch and bound algorithm. These methods work by solving a sequence of linear programming relaxations for the integer programming problem. In addition, the cutting plane methods can approximate the integer programming problem in the best way by enhancing the relaxation of the problem. Moreover, the branch and bound algorithm is implemented by sophisticated divide and conquer approach to solve the problems. A branch and cut algorithm procedure is outlined as shown in Algorithm 1.

Meanwhile, a user supplied routine can be called after a node is applied by the solver in the branch and bound tree. The available information from this node, such as the current incumbency, the branch and bound tree, and the LP solution, is considered in the original namespace of the GAMS database. Then, the solver can call for finding both violated cuts and a better incumbency. The obtained information from the aforementioned GAMS programs must import the found cuts/an integer solution from the solver and export results to another GAMS database, which are imported by the solver after the violated cuts or a better incumbent GAMS program terminate. Thereby, the solver can add the found violated cuts to its cut pool to resolve the linear programming at the node and then, recall the user supplied cut generating GAMS model. The solver will move to the next node if no cutting planes are found. Moreover, it is worthwhile to note that the MIP cuts generation is assigned to an automatic option in the branch and cut algorithm. The computational results were performed on a personal computer with an Intel Core(TM) i7 CPU $3 \mathrm{GHz}$ and 4 GB RAM.

\subsection{Procedure of the presented solution approach}

The presented solution approach, which is implemented to solve the proposed model, is depicted in Figure 4.

1. Initialization of the $M I L P-C M S^{0}$

1.1. Set the active nodes: $S=\left\{M I L P-C M S^{0}\right\}$;

1.2. Set the upper bound: $\mathrm{OFV}^{U}=+\infty$;

1.3. Set the upper bound: $\mathrm{OFV}_{s}^{L}=0 \forall s$;

2. Termination:

2.1. If $S=\phi$, then $x^{*}$ is optimal for $\mathrm{OFV}^{U}$

2.2. Else if $\mathrm{OFV}^{U}=+\infty$ or 0 , then MILP-CMS is infeasible.

3. Problem selection:

3.1. Delete a problem of $M I L P-C M S^{s}$ from $S$

4. Relaxation: Solve the linear programming relation of $M I L P-C M S^{s}$.

4.1. While the relaxation is infeasible, do

4.1.1. Set $\mathrm{OFV}_{s}^{L}=\infty$

4.1.2. If $\mathrm{OFV}_{s}^{L} \geq \mathrm{OFV}^{U}$

4.1.2.1. If $S=\phi$, then $x^{*}$ is optimal for $\mathrm{OFV}^{U}$

4.1.2.2. Else if $\mathrm{OFV}^{U}=+\infty$ or 0 , then MILP-CMS is infeasible.

4.1.3. If $\mathrm{OFV}_{s}^{L}<\mathrm{OFV}^{U}$ and $x^{L R}$ is integrally feasible

4.1.3.1. Set $\mathrm{OFV}_{s}^{L}=\mathrm{OFV}^{U}$

4.1.3.2. Delete all problems with $\mathrm{OFV}_{s}^{L} \geq \mathrm{OFV}^{U}$ from $S$; and do

4.1.3.1. If $S=\phi$, then $x^{*}$ is optimal for $\mathrm{OFV}^{U}$

4.1.3.2. Else if $\mathrm{OFV}^{U}=+\infty$ or 0 , then MILP-CMS is infeasible.

4.1.4. End While.

4.2. If $\mathrm{OFV}_{s}^{L}$ is finite

4.2.1. Let $x^{L R}$ be an optimal solution

4.2.2. Let $\mathrm{OFV}_{s}^{L}$ be an optimal objective value

4.2.3. Otherwise $\mathrm{OFV}_{s}^{L}=0$

5. Add cutting planes: if desired, do

5.1. Add a cutting plane which is violated by $x^{L R}$

5.2. Return to (4).

6. End solution procedure.

Algorithm 1. The branch and cut algorithm procedure. 


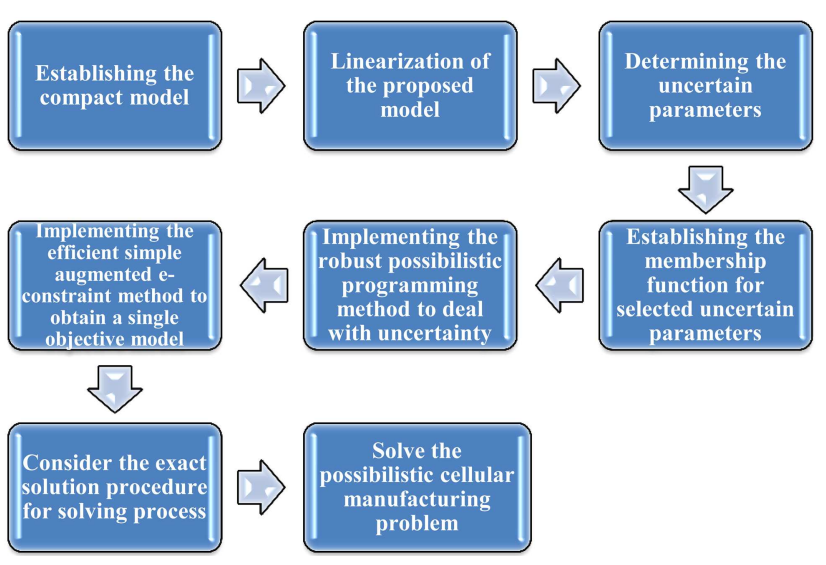

Figure 4. Hierarchical structure of the presented solution approach.

\section{Case study}

In this section, a real case study is provided to show the validity and applicability of the proposed model. To this end, the performance of the proposed model is indicated during the four periods. In the following, the outline of the case study is provided and then, the results obtained from applying the proposed model are discussed.

\subsection{Outline of the case study}

The case study is the assignment of different machines to cells along four periods in an XYZ company. Due to limitation in implementation, the managers of the company cannot reconfigure cells during planning periods. In this way, products should be produced in designed cells based on customers' demand and requested qualities through four periods. According to the XYZ's documents, three types of machines and workers are available with three levels of harnesses and skills, respectively. To illustrate the interaction between workers' skills, machine hardness, and quality of products, the managers and directory board members of XYZ company have defined the following rules:

Rule 1. If hardness of a job $j$ on a machine $m$ is low and the worker $w$ is beginner, then the output of job $j$ has medium $\left(q_{2}\right)$ quality;

Rule 2. If hardness of a job $j$ on a machine $m$ is low and the worker $w$ is semi-skilled, then the output of job $j$ has high $\left(q_{1}\right)$ quality;

Rule 3. If hardness of a job $j$ on a machine $m$ is low and the worker $w$ is expert then the output of job $j$ has high $\left(q_{1}\right)$ quality;

Rule 4. If hardness of a job $j$ on a machine $m$ is moderate and the worker $w$ is beginner, then the output of job $j$ has low $\left(q_{3}\right)$ quality;

Rule 5. If hardness of a job $j$ on a machine $m$ is moderate and the worker $w$ is semi-skilled, then the output of job $j$ has medium $\left(q_{2}\right)$ quality;

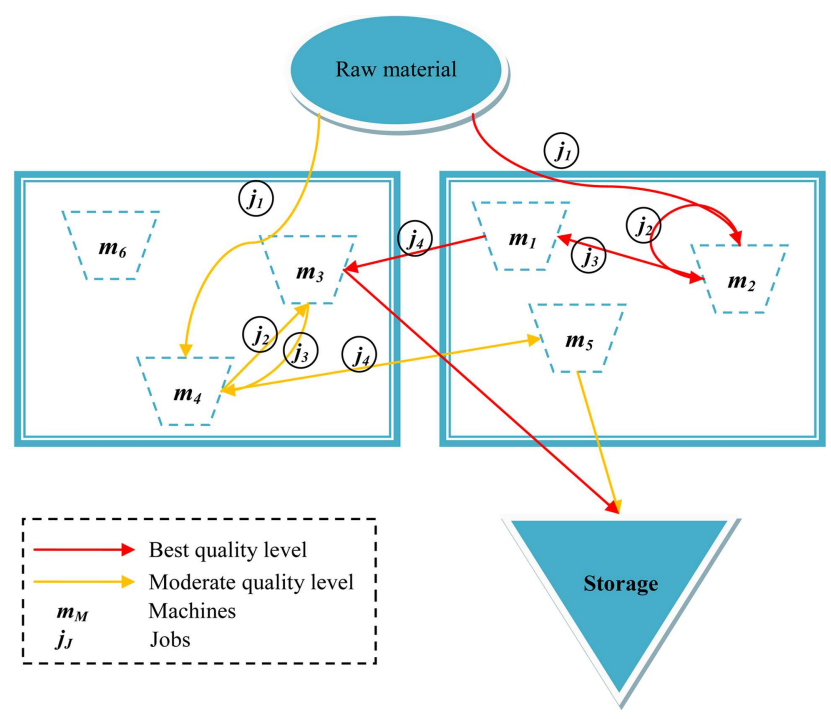

Figure 5. The process of the 4 th product with the best and moderate quality levels regarding the required jobs on each machine.

Rule 6. If hardness of a job $j$ on a machine $m$ is moderate and the worker $w$ is expert, then the output of job $j$ has high $\left(q_{1}\right)$ quality;

Rule 7. If hardness of a job $j$ on a machine $m$ is high, then the beginner worker cannot be assigned to it;

Rule 8. If hardness of a job $j$ on a machine $m$ is high and the worker $w$ is semi-skilled, then the output of job $j$ has low $\left(q_{3}\right)$ quality;

Rule 9. If hardness of a job $j$ on a machine $m$ is high and the worker $w$ is expert, then the output of job $j$ has high $\left(q_{1}\right)$ quality.

Other parameters of the proposed model are gathered by interviewing XYZ managers from different departments, and considering company's documents. For instance, the skill level of each worker on each machine is defined as fuzzy input parameters in Table 3.

\subsection{Obtained results}

In this section, the results obtained from the proposed bi-objective possibilistic nonlinear mixed-integer programming model are presented. The proposed model is solved using the exact solution procedure. The results show that two cells should be formed; assignments of each machine $\left(X_{m k}\right)$ to these two cells are presented in Table 4.

In addition, the total demand of customers is satisfied during the planning horizon and demonstrated in Table 5. Furthermore, the production process for each product with a specific quality level $\left(Y_{j p m}^{k q}\right)$ regarding the required jobs and machines is determined. In this respect, Figure 5 shows the production process of the 
Table 3. The skill levels of each worker on each machine $\left(S_{w m}^{s}\right)$.

\begin{tabular}{|c|c|c|c|}
\hline \multirow{2}{*}{$\begin{array}{c}\text { Skills } \\
\text { level }\end{array}$} & \multirow{2}{*}{ Machines } & \multicolumn{2}{|c|}{ Workers } \\
\hline & & $w=1$ & $w=2$ \\
\hline Expert & & $\tilde{S}_{11}^{1}=(U[0.6,0.65], U[0.7,0.8], U[0.85,0.95])$ & $\tilde{S}_{21}^{1}=(U[0.05,0.15], U[0.15,0.2], U[0.2,0.35])$ \\
\hline Semi-skilled & $m=1$ & $\tilde{S}_{11}^{2}=(U[0.3,0.35], U[0.4,0.45], U[0.5,0.6])$ & $\tilde{S}_{21}^{2}=(U[0.35,0.45], U[0.5,0.6], U[0.65,0.75])$ \\
\hline Beginner & & $\tilde{S}_{11}^{3}=(U[0.0,0.15], U[0.2,0.25], U[0.25,0.3])$ & $\tilde{S}_{21}^{3}=(U[0.7,0.75], U[0.75,0.8], U[0.9,0.95])$ \\
\hline Expert & & $\tilde{S}_{12}^{1}=(U[0.0,0.05], U[0.1,0.15], U[0.25,0.3])$ & $\tilde{S}_{22}^{1}=(U[0.8,0.825], U[0.85,0.9], U[0.9,0.95])$ \\
\hline Semi-skilled & $m=2$ & $\tilde{S}_{12}^{2}=(U[0.35,0.4], U[0.4,0.45], U[0.50,0.6])$ & $\tilde{S}_{22}^{2}=(U[0.4,0.45], U[0.5,0.6], U[0.65,0.75])$ \\
\hline Beginner & & $\tilde{S}_{12}^{3}=(U[0.65,0.75], U[0.75,0.8], U[0.80,0.95])$ & $\tilde{S}_{22}^{3}=(U[0.1,0.15], U[0.15,0.2], U[0.25,0.35])$ \\
\hline Expert & & $\tilde{S}_{13}^{1}=(U[0.55,0.60], U[0.65,0.75], U[0.80,0.95])$ & $\tilde{S}_{23}^{1}=(U[0.30,0.45], U[0.5,0.6], U[0.65,0.75])$ \\
\hline Semi-skilled & $m=3$ & $\tilde{S}_{13}^{2}=(U[0.25,0.30], U[0.35,0.45], U[0.50,0.55])$ & $\tilde{S}_{23}^{2}=(U[0.65,0.75], U[0.75,0.8], U[0.8,0.9])$ \\
\hline Beginner & & $\tilde{S}_{13}^{3}=(U[0.05,0.10], U[0.15,0.2], U[0.20,0.25])$ & $\tilde{S}_{23}^{3}=(U[0.35,0.45], U[0.55,0.6], U[0.65,0.70])$ \\
\hline Expert & & $\tilde{S}_{14}^{1}=(U[0.2,0.3], U[0.35,0.45], U[0.5,0.55])$ & $\tilde{S}_{24}^{1}=(U[0.0,0.05], U[0.1,0.25], U[0.25,0.3])$ \\
\hline Semi-skilled & $m=4$ & $\tilde{S}_{14}^{2}=(U[0.60,0.7], U[0.7,0.8], U[0.80,0.95])$ & $\tilde{S}_{24}^{2}=(U[0.25,0.35], U[0.35,0.40], U[0.45,0.55])$ \\
\hline Beginner & & $\tilde{S}_{14}^{3}=(U[0.3,0.35], U[0.35,0.4], U[0.4,0.55])$ & $\tilde{S}_{24}^{3}=(U[0.6,0.65], U[0.7,0.8], U[0.85,0.95])$ \\
\hline Expert & & $\tilde{S}_{15}^{1}=(U[0.2,0.3], U[0.35,0.55], U[0.55,0.65])$ & $\tilde{S}_{25}^{1}=(U[0.6,0.75], U[0.75,0.8], U[0.8,0.9])$ \\
\hline Semi-skilled & $m=5$ & $\tilde{S}_{15}^{2}=(U[0.7,0.75], U[0.75,0.8], U[0.85,0.95])$ & $\tilde{S}_{25}^{2}=(U[0.275,0.35], U[0.35,0.45], U[0.45,0.6])$ \\
\hline Beginner & & $\tilde{S}_{15}^{3}=(U[0.2,0.25], U[0.35,0.5], U[0.55,0.60])$ & $\tilde{S}_{25}^{3}=(U[0.05,0.1], U[0.1,0.2], U[0.2,0.3])$ \\
\hline Expert & & $\tilde{S}_{16}^{1}=(U[0.05,0.15], U[0.15,0.2], U[0.25,0.3])$ & $\tilde{S}_{26}^{1}=(U[0.75,0.8], U[0.8,0.85], U[0.85,0.95])$ \\
\hline Semi-skilled & $m=6$ & $\tilde{S}_{16}^{2}=(U[0.4,0.45], U[0.5,0.6], U[0.65,0.75])$ & $\tilde{S}_{26}^{2}=(U[0.35,0.425], U[0.45,0.5], U[0.5,0.55])$ \\
\hline \multirow[t]{2}{*}{ Beginner } & & $\tilde{S}_{16}^{3}=(U[0.65,0.75], U[0.75,0.8], U[0.85,0.9])$ & $\tilde{S}_{26}^{3}=(U[0.1,0.15], U[0.2,0.25], U[0.25,0.325])$ \\
\hline & & $w=3$ & $w=4$ \\
\hline Expert & & $\tilde{S}_{31}^{1}=(U[0.25,0.4], U[0.4,0.45], U[0.45,0.6])$ & $\tilde{S}_{41}^{1}=(U[0.05,0.15], U[0.15,0.25], U[0.25,0.3])$ \\
\hline Semi-skilled & $m=1$ & $\tilde{S}_{31}^{2}=(U[0.75,0.8], U[0.8,0.85], U[0.85,0.9])$ & $\tilde{S}_{41}^{2}=(U[0.35,0.45], U[0.5,0.6], U[0.65,0.75])$ \\
\hline Beginner & & $\tilde{S}_{31}^{3}=(U[0.35,0.4], U[0.4,0.5], U[0.50,0.6])$ & $\tilde{S}_{41}^{3}=(U[0.7,0.75], U[0.75,0.8], U[0.8,0.9])$ \\
\hline Expert & & $\tilde{S}_{32}^{1}=(U[0.25,0.3], U[0.35,0.55], U[0.55,0.65])$ & $\tilde{S}_{42}^{1}=(U[0.0,0.15], U[0.15,0.25], U[0.25,0.3])$ \\
\hline Semi-skilled & $m=2$ & $\tilde{S}_{32}^{2}=(U[0.65,0.75], U[0.75,0.8], U[0.85,0.90])$ & $\tilde{S}_{42}^{2}=(U[0.3,0.4], U[0.4,0.45], U[0.45,0.6])$ \\
\hline Beginner & & $\tilde{S}_{32}^{3}=(U[0.2,0.3], U[0.35,0.5], U[0.55,0.60])$ & $\tilde{S}_{42}^{3}=(U[0.50,0.60], U[0.65,0.75], U[0.80,0.95])$ \\
\hline Expert & & $\tilde{S}_{33}^{1}=(U[0.6,0.7], U[0.7,0.8], U[0.85,0.90])$ & $\tilde{S}_{43}^{1}=(U[0.25,0.3], U[0.3,0.45], U[0.5,0.55])$ \\
\hline Semi-skilled & $m=3$ & $\tilde{S}_{33}^{2}=(U[0.3,0.35], U[0.35,0.45], U[0.45,0.55])$ & $\tilde{S}_{43}^{2}=(U[0.65,0.7], U[0.7,0.8], U[0.80,0.95])$ \\
\hline Beginner & & $\tilde{S}_{33}^{3}=(U[0.0,0.05], U[0.1,0.15], U[0.25,0.3])$ & $\tilde{S}_{43}^{3}=(U[0.3,0.35], U[0.35,0.5], U[0.5,0.55])$ \\
\hline Expert & & $\tilde{S}_{34}^{1}=(U[0.65,0.75], U[0.7,0.8], U[0.80,0.95])$ & $\tilde{S}_{44}^{1}=(U[0.7,0.75], U[0.85,0.9], U[0.9,0.95])$ \\
\hline Semi-skilled & $m=4$ & $\tilde{S}_{34}^{2}=(U[0.35,0.4], U[0.4,0.45], U[0.50,0.6])$ & $\tilde{S}_{44}^{2}=(U[0.3,0.35], U[0.45,0.55], U[0.55,0.65])$ \\
\hline Beginner & & $\tilde{S}_{34}^{3}=(U[0.05,0.15], U[0.15,0.2], U[0.25,0.3])$ & $\tilde{S}_{44}^{3}=(U[0.0,0.05], U[0.05,0.25], U[0.25,0.3])$ \\
\hline Expert & & $\tilde{S}_{35}^{1}=(U[0.1,0.15], U[0.15,0.25], U[0.25,0.3])$ & $\tilde{S}_{45}^{1}=(U[0.65,0.75], U[0.75,0.8], U[0.85,0.9])$ \\
\hline Semi-skilled & $m=5$ & $\tilde{S}_{35}^{2}=(U[0.35,0.4], U[0.4,0.45], U[0.45,0.6])$ & $\tilde{S}_{45}^{2}=(U[0.3,0.35], U[0.35,0.4], U[0.4,0.55])$ \\
\hline Beginner & & $\tilde{S}_{35}^{3}=(U[0.65,0.75], U[0.7,0.8], U[0.80,0.95])$ & $\tilde{S}_{45}^{3}=(U[0.05,0.15], U[0.15,0.2], U[0.25,0.3])$ \\
\hline Expert & & $\tilde{S}_{36}^{1}=(U[0.25,0.35], U[0.35,0.45], U[0.45,0.55])$ & $\tilde{S}_{46}^{1}=(U[0.2,0.4], U[0.4,0.5], U[0.5,0.6])$ \\
\hline Semi-skilled & $m=6$ & $\tilde{S}_{36}^{2}=(U[0.60,0.75], U[0.75,0.8], U[0.80,0.95])$ & $\tilde{S}_{46}^{2}=(U[0.7,0.8], U[0.8,0.85], U[0.85,0.95])$ \\
\hline Beginner & & $\tilde{S}_{36}^{3}=(U[0.3,0.35], U[0.35,0.4], U[0.45,0.55])$ & $\tilde{S}_{46}^{3}=(U[0.3,0.4], U[0.45,0.5], U[0.50,0.6])$ \\
\hline
\end{tabular}


forth product with the best and moderate quality levels regarding inter-/intra-cell movements, schematically.

Moreover, assignment of workers to perform each job on each machine with a specific skill level $\left(\varpi_{w j m}^{s}\right)$ is performed. For further convenience, assignment of workers regarding their skill levels to the production process of the forth product is demonstrated in Figure 6.

Meanwhile, objective function values of the proposed model reveal that there is a conflict between minimizing the total cost and inaction of workers and machines, simultaneously. A survey of the proposed model indicated that minimizing inactive workers and machines led to increased cost of employment of work-

Table 4. Machine assignment to cells.

\begin{tabular}{ccc}
\hline \multirow{2}{*}{ Machine } & \multicolumn{2}{c}{ Cell } \\
\cline { 2 - 3 } & $\boldsymbol{k}=\mathbf{1}$ & $\boldsymbol{k}=\mathbf{2}$ \\
\hline$m=1$ & 0 & 1 \\
$m=2$ & 0 & 1 \\
$m=3$ & 1 & 0 \\
$m=4$ & 1 & 0 \\
$m=5$ & 0 & 1 \\
$m=6$ & 1 & 0 \\
\hline
\end{tabular}

ers and processing cost of machines, respectively. The conflict between the two considered objective functions is shown in Figure 7, and the obtained Pareto optimal points are presented in Table 6. Therefore, decision makers can select one of the obtained Pareto optimal points, which is the best solution for them.

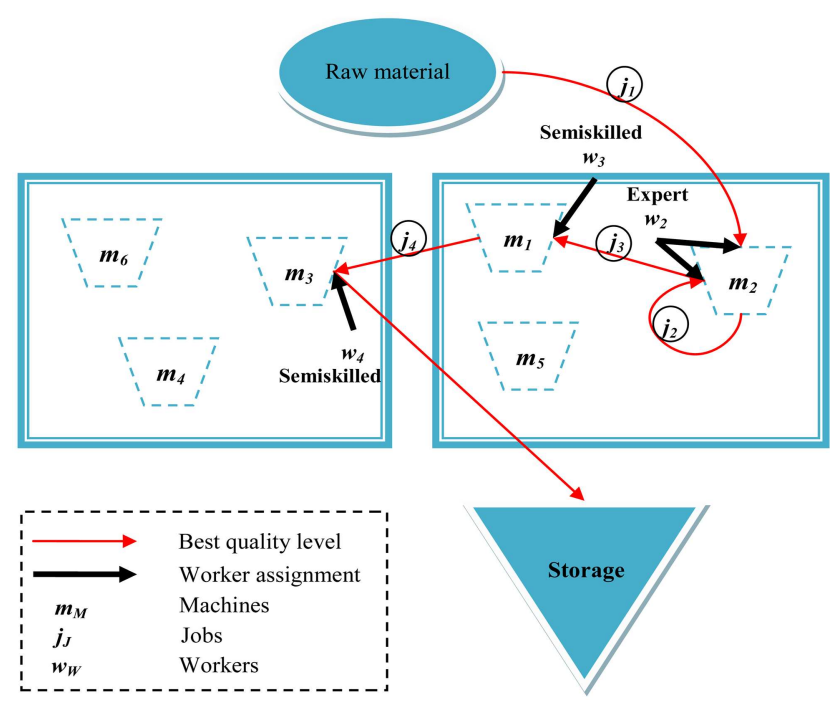

Figure 6. Worker assignment to each machine and job regarding their skill level.

Table 5. Number of products produced with a specific quality level in each period.

\begin{tabular}{|c|c|c|c|c|c|}
\hline \multirow{2}{*}{ Quality level } & \multirow{2}{*}{ Products } & \multicolumn{4}{|c|}{ Period } \\
\hline & & $t=1$ & $t=2$ & $t=3$ & $t=4$ \\
\hline Best quality & & 14 & 20 & 11 & 11 \\
\hline Moderate quality & $p=1$ & 36 & 35 & 39 & 18 \\
\hline Worst quality & & 7 & 5 & 14 & 19 \\
\hline Best quality & & 10 & 11 & 7 & 9 \\
\hline Moderate quality & $p=2$ & 79 & 82 & 45 & 29 \\
\hline Worst quality & & 35 & 45 & 19 & 5 \\
\hline Best quality & & 8 & 9 & 8 & 6 \\
\hline Moderate quality & $p=3$ & 37 & 10 & 17 & 19 \\
\hline Worst quality & & 79 & 53 & 53 & 41 \\
\hline Best quality & & 94 & 28 & 49 & 26 \\
\hline Moderate quality & $p=4$ & 59 & 7 & 39 & 13 \\
\hline Worst quality & & 86 & 35 & 18 & 17 \\
\hline Best quality & & 13 & 14 & 6 & 7 \\
\hline Moderate quality & $p=5$ & 29 & 54 & 16 & 10 \\
\hline Worst quality & & 11 & 8 & 6 & 9 \\
\hline Best quality & & 6 & 16 & 14 & 11 \\
\hline Moderate quality & $p=6$ & 47 & 97 & 45 & 16 \\
\hline Worst quality & & 25 & 9 & 11 & 13 \\
\hline
\end{tabular}




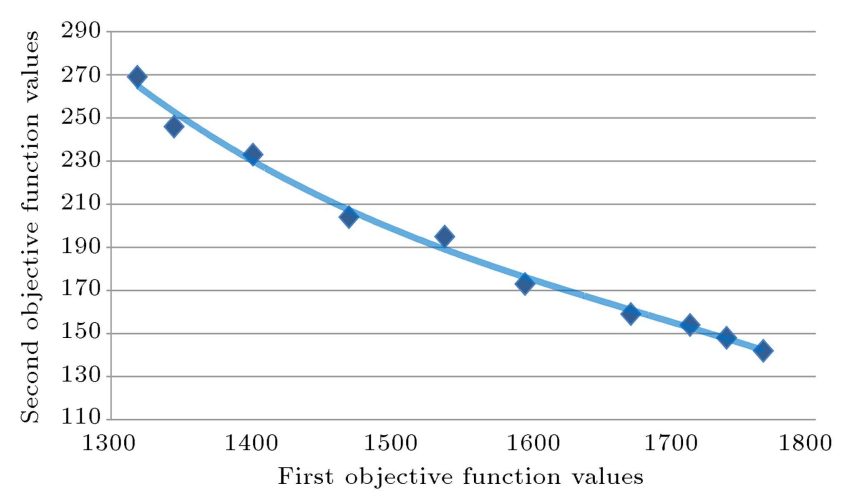

Figure 7. Schematic representation of the conflict between the objective functions.

Table 6. The best values of the objective functions.

\begin{tabular}{ccc}
\hline \multirow{2}{*}{$\begin{array}{c}\text { Pareto } \\
\text { optimal } \\
\text { point }\end{array}$} & \multicolumn{2}{c}{$\begin{array}{c}\text { The values of } \\
\text { objective functions }\end{array}$} \\
\cline { 2 - 3 } & Objective $\mathbf{1}$ & Objective 2 \\
\hline 1 & 1319 & 269 \\
2 & 1345 & 246 \\
3 & 1401 & 233 \\
4 & 1469 & 204 \\
5 & 1537 & 195 \\
6 & 1594 & 173 \\
7 & 1669 & 159 \\
8 & 1711 & 154 \\
9 & 1737 & 148 \\
10 & 1763 & 142 \\
\hline
\end{tabular}

The obtained Pareto optimal points of objective functions have been approved by experts. In this respect, considering the worst Pareto optimal points of the first and second objective functions shows that the proposed approach can reduce the total costs by $23.6 \%$ and the total inaction of workers and machines by $11.7 \%$.

\section{Sensitivity analysis}

A sensitivity analysis is provided to clarify the robustness and sensitiveness of the proposed possibilistic mixed integer programming model regarding important parameters for managing CMS based on product quality level, worker's skill level, and machine hardness level in real cases. Here, considering different workers with various skill levels as well as different machines with various hardness levels could lead to different values for objective functions.

In this respect, the number of workers with various skill levels is recognized as an important parameter to identify its effects on the objective functions. Meanwhile, the effects of changing the employed workers

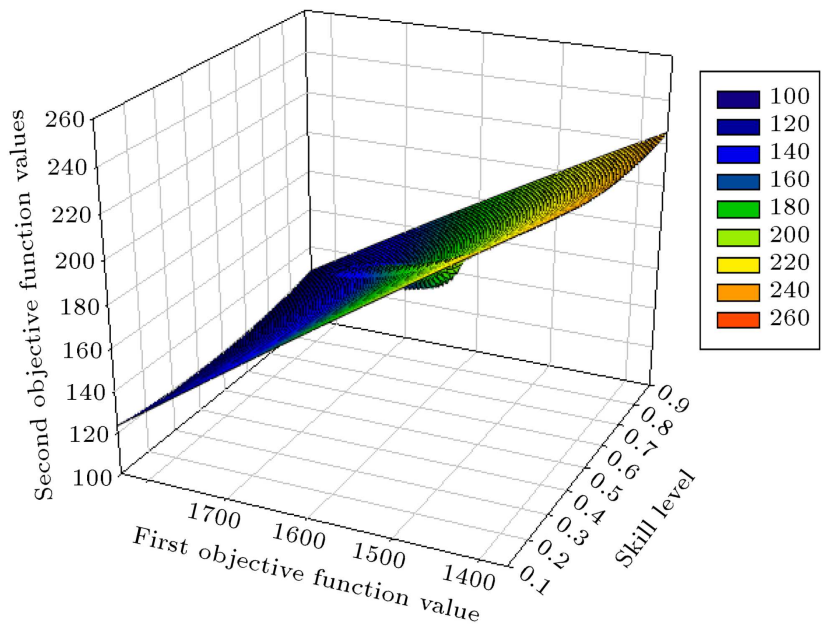

Figure 8. The effect of different skill levels of workers on the objective functions.

with various skill levels (i.e., expert, semi-skilled, and beginner) on the values of the objective functions are examined. The results show that considering workers with beginner and expert skill levels leads to the minimum and maximum values of the objective functions, respectively.

Therefore, the skill level of workers is changed to represent its effects on both the objective functions. As indicated in Figure 8, by increasing workers' skill level, the total costs of CMS problems increase. Moreover, the value of the second objective function for minimizing the inactive workers and machines is obtained lower than the determined Pareto optimal points from solving the case study. Although the cost of employing workers with high skill level increases, lower value for workers' inactivation is obtained. In addition, it is clear that a company with highly skilled workers could manufacture products with the best quality. Moreover, such workers could appropriately operate jobs on different machines with various hardness levels. Thereby, the hole in Figure 8 indicates that selecting the Pareto optimal midpoints may be a suitable decision for minimizing both the objective functions by ensuring the CMS problem competencies.

Furthermore, one of the main parameters is jobs with various hardness levels on each machine, which could lead to different costs. Accordingly, the number of machines with different job hardness levels (i.e., low, moderate, and high) are changed so that their effectiveness on both the objective functions of the proposed possibilistic mixed integer programming model could be determined. The results show that the trend of the cost variation with regard to change in the number of machines with various job hardness levels is increasing. On the other hand, job hardness level for machines is increased to identify the robustness or sensitiveness of both the objective functions. As indicated in Figure 9, the total cost of the CMS problem $\left(Z_{T C}\right)$ increases 


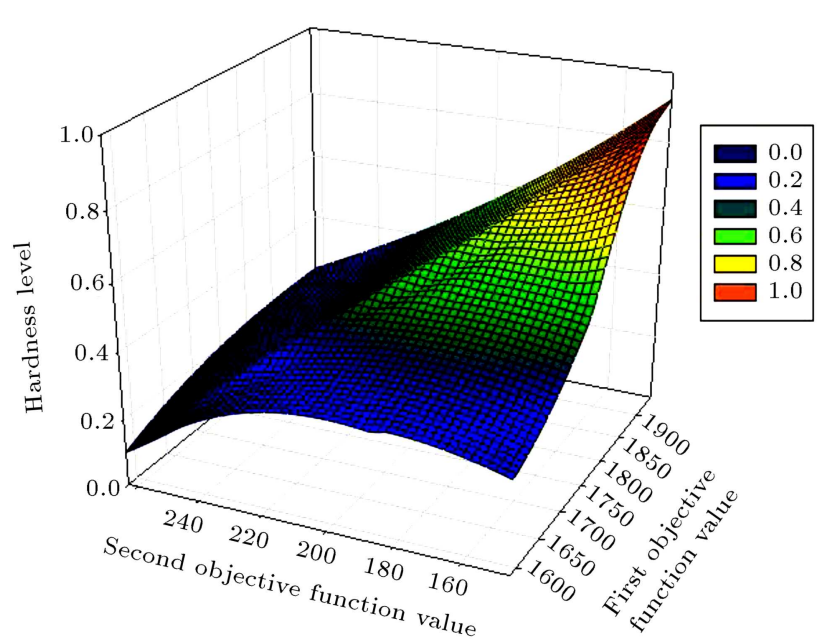

Figure 9. The effect of different jobs' hardness levels on the objective functions.

with high job hardness level. In contrast, the second objective function values $\left(Z_{I A}\right)$ change around the obtained values for the case study. It is shown that job hardness level of machines cannot directly affect inactivation of workers and machines. To address the issue, the Hamming or Euclidean distance measure could be considered. These measures show how much the Pareto optimal points obtained from the second objective function for the case study and the sensitivity analysis are close to each other.

However, considering the output quality of the manufactured product is more important with regard to lowering of the total costs and inactivation of workers or machines. This is because the customer satisfaction could directly lead the company towards a successful business. To address the issue, simultaneous consideration of workers with different skill levels and machines with different hardness levels is more significant. Indeed, skill levels of workers and hardness levels of machines could affect the output quality. Therefore, considering the optimum combination of workers with suitable skill levels and machines with appropriate hardness levels could decrease the total costs and inactivation of workers and machines as well as preserve the required quality level of manufactured products. Ultimately, this study could assist decision makers to overcome this challenge by selecting the appropriate Pareto optimal point.

\section{Conclusions and future directions}

Design of appropriate Cellular Manufacturing Systems (CMSs) involves many operational and structural issues. In this respect, some significant issues such as product quality level, worker's skill level, and machine hardness level should be taken into consideration to help companies in the current competitive environment. In this study, a novel bi-objective pos- sibilistic nonlinear mixed-integer programming model under imprecise condition was presented in order to minimize the total costs and total inaction of workers and machines. The proposed model was incorporated into dynamic cell formation, worker and machine assignments, machine hardness level, route and worker flexibility, operation sequence, product quality level, worker and machine capacity, and worker's skill level under uncertainty. Then, some important parameters were considered for fuzziness based on literature survey and the nature of the parameters. In this respect, the robust possibilistic programming approach was utilized to address the uncertain parameters in the proposed model. Hence, the presented model was implemented for a real case study to show the capability and efficiency of the proposed novel possibilistic mathematical model. Comparing the results obtained from the proposed model and the current actual practice showed that the presented model could help companies minimize their costs and appropriately manipulate workers and machines. Furthermore, the sensitivity analysis showed that changing workers' skill level could affect both the objective functions of the proposed approach. In contrast, the first and second objective functions were sensitive and robust to different job hardness levels of machines, respectively. For future research, considering the inventory level, lot splitting, and flexible reconfiguration features can enhance the performance of the proposed model. In addition, developing heuristic algorithms to solve large-size problems is suggested.

\section{References}

1. Wemmerlöv, U. and Hyer, N.L. "Procedures for the part family/machine group identification problem in cellular manufacturing", Journal of Operations Management, 6(2), pp. 125-147 (1986).

2. Aalaei, A. and Davoudpour, H. "A robust optimization model for cellular manufacturing system into supply chain management", International Journal of Production Economics, 183, pp. 667-679 (2017).

3. Rafiei, H. and Ghodsi, R. "A bi-objective mathematical model toward dynamic cell formation considering labor utilization", Applied Mathematical Modelling, 37(4), pp. 2308-2316 (2013).

4. Rheault, M., Drolet, J.R., and Abdulnour, G. "Physically reconfigurable virtual cells: a dynamic model for a highly dynamic environment", Computers \& Industrial Engineering, 29(1), pp. 221-225 (1995).

5. Rosenblatt, M.J. "The dynamics of plant layout", Management Science, 32(1), pp. 76-86 (1986).

6. Mahdavi, I., Aalaei, A., Paydar, M.M., and Solimanpur, M. "Designing a mathematical model for dynamic cellular manufacturing systems considering production planning and worker assignment", Computers \& 
Mathematics with Applications, 60(4), pp. 1014-1025 (2010).

7. Saxena, L.K. and Jain, P.K. "Dynamic cellular manufacturing systems design-a comprehensive model", The International Journal of Advanced Manufacturing Technology, 53(1-4), pp. 11-34 (2011).

8. Paydar, M.M., Saidi-Mehrabad, M., and Kia, R. "Designing a new integrated model for dynamic cellular manufacturing systems with production planning and intra-cell layout", International Journal of Applied Decision Sciences, 6(2), pp. 117-143 (2013).

9. Kia, R., Javadian, N., and Tavakkoli-Moghaddam, R. "A simulated annealing algorithm to determine a group layout and production plan in a dynamic cellular manufacturing system", Journal of Optimization in Industrial Engineering, 7(14), pp. 37-52 (2014).

10. Norman, B.A., Tharmmaphornphilas, W., Needy, K.L., Bidanda, B., and Warner, R.C. "Worker assignment in cellular manufacturing considering technical and human skills", International Journal of Production Research, 40(6), pp. 1479-1492 (2002).

11. Suksawat, B., Hiraoka, H., and Ihara, T. "A new approach manufacturing cell scheduling based on skill-based manufacturing integrated to genetic algorithm", In Towards Synthesis of Micro-/NanoSystems, Springer, pp. 325-326 (2007).

12. Duan, F., Tan, J.T.C., Tong, J.G., Kato, R., and Arai, T. "Application of the assembly skill transfer system in an actual cellular manufacturing system", Automation Science and Engineering, IEEE Transactions on, 9(1), pp. 31-41 (2012).

13. Egilmez, G., Erenay, B., and Süer, G.A. "Stochastic skill-based manpower allocation in a cellular manufacturing system", Journal of Manufacturing Systems, 33(4), pp. 578-588 (2014).

14. Lim, Z.Y., Ponnambalam, S., and Izui, K. "Multiobjective hybrid algorithms for layout optimization in multi-robot cellular manufacturing systems", Knowledge-Based Systems, 120, pp. 87-98 (2017).

15. Rezazadeh, H. and Khiali-Miab, A. "A two-layer genetic algorithm for the design of reliable cellular manufacturing systems", International Journal of Industrial Engineering Computations, 8(3), pp. 315-332 (2017).

16. Aalaei, A. and Davoudpour, H. "Revised multi-choice goal programming for incorporated dynamic virtual cellular manufacturing into supply chain management: a case study", Engineering Applications of Artificial Intelligence, 47, pp. 3-15 (2016).

17. Forghani, K. and Mohammadi, M. "A genetic algorithm for solving integrated cell formation and layout problem considering alternative routings and machine capacities", Scientia Iranica. Transaction E, Industrial Engineering, 21(6), pp. 2326-2346 (2014).
18. Sahinidis, N.V. "Optimization under uncertainty: state-of-the-art and opportunities", Computers \& Chemical Engineering, 28(6), pp. 971-983 (2004).

19. Mirzapour Al-E-Hashem, S., Malekly, H., and Aryanezhad, M. "A multi-objective robust optimization model for multi-product multi-site aggregate production planning in a supply chain under uncertainty", International Journal of Production Economics, 134(1), pp. 28-42 (2011).

20. Safaei, N. and Tavakkoli-Moghaddam, R. "An extended fuzzy parametric programming-based approach for designing cellular manufacturing systems under uncertainty and dynamic conditions", International Journal of Computer Integrated Manufacturing, 22(6), pp. 538-548 (2009).

21. Kia, R., Paydar, M.M., Jondabeh, M.A., Javadian, N., and Nejatbakhsh, Y. "A fuzzy linear programming approach to layout design of dynamic cellular manufacturing systems with route selection and cell reconfiguration", International Journal of Management Science and Engineering Management, 6(3), pp. 219230 (2011).

22. Behret, H. and Satoglu, S.I. "Fuzzy logic applications in cellular manufacturing system design", In Computational Intelligence Systems in Industrial Engineering, Springer, pp. 505-533 (2012).

23. Paydar, M.M. and Saidi-Mehrabad, M. "Revised multi-choice goal programming for integrated supply chain design and dynamic virtual cell formation with fuzzy parameters", International Journal of Computer Integrated Manufacturing, 28(3), pp. 251-265 (2014).

24. Tavakkoli-Moghaddam, R., Javadian, N., Javadi, B., and Safaei, N. "Design of a facility layout problem in cellular manufacturing systems with stochastic demands", Applied Mathematics and Computation, 184(2), pp. 721-728 (2007).

25. Ghezavati, V. and Saidi-Mehrabad, M. "Designing integrated cellular manufacturing systems with scheduling considering stochastic processing time", The International Journal of Advanced Manufacturing Technology, 48(5-8), pp. 701-717 (2010).

26. Ghezavati, V. and Saidi-Mehrabad, M. "An efficient hybrid self-learning method for stochastic cellular manufacturing problem: A queuing-based analysis", Expert Systems with Applications, 38(3), pp. 13261335 (2011).

27. Egilmez, G., Süer, G.A., and Huang, J. "Stochastic cellular manufacturing system design subject to maximum acceptable risk level", Computers \& Industrial Engineering, 63(4), pp. 842-854 (2012).

28. Salarian, R., Fazlollahtabar, H., and Mahdavi, I. "Inter-cell movement minimisation in a cellular manufacturing system having stochastic parameters", International Journal of Services and Operations Management, 17(1), pp. 67-87 (2014). 
29. Bagheri, M., Sadeghi, S., and Saidi-Mehrabad, M. "A benders decomposition approach for dynamic cellular manufacturing system in the presence of unreliable machines", Journal of Optimization in Industrial Engineering, 8(17), pp. 37-49 (2015).

30. Rabbani, M., Akbari, E., and Dolatkhah, M. "Manpower allocation in a cellular manufacturing system considering the impact of learning, training and combination of learning and training in operator skills", Management Science Letters, 7(1), pp. 9-22 (2017).

31. Ghezavati, V., Sadjadi, S., and Dehghan Nayeri, M. "Integrating strategic and tactical decisions to robust designing of cellular manufacturing under uncertainty: Fixed suppliers in supply chain", International Journal of Computational Intelligence Systems, 4(5), pp. 837854 (2011).

32. Forghani, K., Mohammadi, M., and Ghezavati, V. "Designing robust layout in cellular manufacturing systems with uncertain demands", International Journal of Industrial Engineering Computations, 4(2), pp. 215226 (2013).

33. Tavakkoli-Moghaddam, R., Sakhaii, M., and Vatani, B. "A robust model for a dynamic cellular manufacturing system with production planning", International Journal of Engineering-Transactions A: Basics, 27(4), pp. 587-598 (2013).

34. Sakhaii, M., Tavakkoli-Moghaddam, R., Bagheri, M., and Vatani, B. "A robust optimization approach for an integrated dynamic cellular manufacturing system and production planning with unreliable machines", Applied Mathematical Modelling, 40(1), pp. 169-191 (2016).

35. Paydar, M.M. and Saidi-Mehrabad, M. "Revised multi-choice goal programming for integrated supply chain design and dynamic virtual cell formation with fuzzy parameters", International Journal of Computer Integrated Manufacturing, 28(3), pp. 251-265 (2015).

36. Pishvaee, M., Razmi, J., and Torabi, S. "Robust possibilistic programming for socially responsible supply chain network design: A new approach", Fuzzy Sets and Systems, 206, pp. 1-20 (2012).

37. Zhang, W. and Reimann, M. "A simple augmented $\epsilon$-constraint method for multi-objective mathematical integer programming problems", European Journal of Operational Research, 234(1), pp. 15-24 (2014).

38. Defersha, F.M. and Chen, M. "A comprehensive mathematical model for the design of cellular manufacturing systems", International Journal of Production Economics, 103(2), pp. 767-783 (2006).

39. Mahdavi, I., Aalaei, A., Paydar, M.M., and Solimanpur, M. "Production planning and cell formation in dynamic virtual cellular manufacturing systems with worker flexibility", In Computers \& Industrial Engineering, 2009. CIE 2009, International Conference on. 2009: IEEE (2009).
40. Solimanpur, M., Saeedi, S., and Mahdavi, I. "Solving cell formation problem in cellular manufacturing using ant-colony-based optimization", The International Journal of Advanced Manufacturing Technology, 50(912), pp. 1135-1144 (2010).

41. Mahdavi, I., Aalaei, A., Paydar, M.M., and Solimanpur, M. "Multi-objective cell formation and production planning in dynamic virtual cellular manufacturing systems", International Journal of Production Research, 49(21), pp. 6517-6537 (2011).

42. Kia, R., Baboli, A., Javadian, N., TavakkoliMoghaddam, R., Kazemi, M., and Khorrami, J. "Solving a group layout design model of a dynamic cellular manufacturing system with alternative process routings, lot splitting and flexible reconfiguration by simulated annealing", Computers \& Operations Research, 39(11), pp. 2642-2658 (2012).

43. Torabi, S. and Amiri, A.S. "A possibilistic approach for designing hybrid cellular manufacturing systems", International Journal of Production Research, 50(15), pp. 4090-4104 (2012).

44. Chang, C.-C., Wu, T.-H., and Wu, C.-W. "An efficient approach to determine cell formation, cell layout and intracellular machine sequence in cellular manufacturing systems", Computers \& Industrial Engineering, 66(2), pp. 438-450 (2013).

45. Kia, R., Shirazi, H., Javadian, N., and TavakkoliMoghaddam, R. "A multi-objective model for designing a group layout of a dynamic cellular manufacturing system", Journal of Industrial Engineering International, 9(1), pp. 1-14 (2013).

46. Shirazi, H., Kia, R., Javadian, N., and TavakkoliMoghaddam, R. "An archived multi-objective simulated annealing for a dynamic cellular manufacturing system", Journal of Industrial Engineering International, 10(2), pp. 1-17 (2014).

47. Deep, K. and Singh, P.K. "Design of robust cellular manufacturing system for dynamic part population considering multiple processing routes using genetic algorithm", Journal of Manufacturing Systems, 35, pp. $155-163$ (2015).

\section{Biographies}

Arash Hashemoghli is currently $\mathrm{PhD}$ candidate in the Department of Industrial Engineering at Science and Technology University of Mazandaran, Babol, Iran. He received BSc and MSc degrees from the School of Industrial Engineering at Science and Technology University of Mazandaran and the Eastern Mediterranean University of Turkish Republic of North Cyprus, respectively. His main research interests include fuzzy sets theory, multi-criteria decision-making under uncertainty, artificial neural networks and applied operations research, and cellular manufacturing systems. 
Iraj Mahdavi is Professor of Industrial Engineering and Vice President of Graduate Studies and Research at Mazandaran University of Science and Technology. He received his $\mathrm{PhD}$ in India in Production Engineering and Post-Doctorate from Hanyang University, Korea. He is also in the editorial board of four journals. He has published over 100 research papers. His research interests include cellular manufacturing, digital management of industrial enterprises, intelligent operation management, and industrial strategy setting.
Ali Tajdin is an Assistant Professor in the Department of Industrial Engineering, Mazandaran University of Science and Technology, Babol, Iran. He received $\mathrm{PhD}$ degree from the Department of Industrial Engineering, Mazandaran University of Science and Technology. His main research interests include optimization and quantitative methods, fuzzy computing, operation research, statistics, and computational methods. He has published many papers and book chapters in reputable journals and international conference proceedings. 